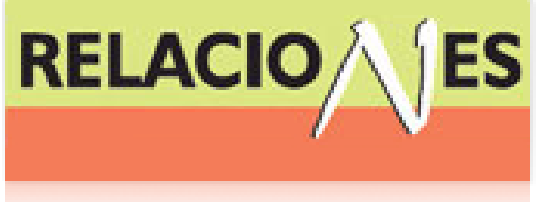

Relaciones. Estudios de historia y sociedad ISSN: 0185-3929

relacion@colmich.edu.mx

El Colegio de Michoacán, A.C

México

Wright Carr, David Charles

Los signos glotográficos en el Códice de Huichapan

Relaciones. Estudios de historia y sociedad, vol. XXXIII, núm. 132, 2012, pp. 33-73

El Colegio de Michoacán, A.C

Zamora, México

Disponible en: http://www.redalyc.org/articulo.oa?id=13725134002

- Cómo citar el artículo

- Número completo

- Más información del artículo

Página de la revista en redalyc.org

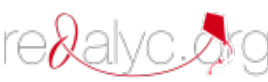

Sistema de Información Científica

Red de Revistas Científicas de América Latina, el Caribe, España y Portugal Proyecto académico sin fines de lucro, desarrollado bajo la iniciativa de acceso abierto 


\title{
Los signos glotográficos en el Códice de Huichapan
}

\author{
David Charles Wright Carr* \\ UNIVERSIDAD DE GUANAJUATO
}

El Códice de Huichapan es un manuscrito histórico del periodo Novohispano Temprano que emplea el sistema de escritura pictórica del Centro de México, junto con textos alfabéticos en otomí, así como algunas glosas aisladas en náhuatl. Estas características permiten poner a prueba la hipótesis de que la mayor parte de los grafemas pictóricos centromexicanos podían ser leídos en varias lenguas por su carácter semasiográfico, mientras algunos signos eran glotogramas que expresan estructuras lingüísticas en un idioma determinado.

(Semasiografía, glotografía, otomíes, Huichapan)

\section{INTRODUCCIÓN}

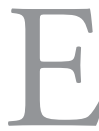

n el presente trabajo ${ }^{1}$ se registran los resultados del análisis hecho de los signos gráficos pintados en el Códice de Huichapan, un manuscrito pictórico y alfabético elaborado hacia 1632. La parte alfabética, por lo menos, fue escrita por el amanuen-

*dcwright@prodigy.net.mx

${ }^{1}$ Este artículo es un extracto sintético de los capítulos 3 y 4 de mi tesis doctoral: "Los otomíes: cultura, lengua y escritura”, tesis, 2 vols., Zamora, Doctorado en Ciencias Sociales, El Colegio de Michoacán, 2005. Para trabajos preliminares sobre los signos gráficos del Códice de Huichapan, elaborados durante las fases iniciales de este proyecto, véanse dos obras del autor del presente artículo: "Signos toponímicos en el Códice de Huichapan”, en Estudios de Cultura Otopame (Instituto de Investigaciones Antropológicas, Universidad Nacional Autónoma de México), núm. 2, 2000, 45-72; "Comunicación gráfica en el Códice de Huichapan”, en Memoria del IV Coloquio Nacional sobre Otopames, David Charles Wright Carr, coordinador, Guanajuato, Departamento de Historia, División de Ciencias Sociales y Humanidades, Campus Guanajuato, Universidad de Guanajuato/ Comité Académico de los Coloquios Internacionales sobre Otopames, 2010, 61-75. 
se Juan de San Francisco, otomí noble del pueblo de Huichapan, y habla de la historia de este pueblo otomí desde 1539 hasta $1632 .{ }^{2}$ La parte pictórica de este documento, además de presentar una nómina de los pueblos del señorío de Xilotépec, narra la historia de este señorío desde el año 2 caña (1403) hasta 10 pedernal (1528), un total de 126 ańos. Es probable que sea una copia de algún manuscrito del siglo XVI, hoy perdido. ${ }^{3}$

${ }^{2}$ En 2001, cuando salió a luz la transcripción y traducción que hizo Lawrence Ecker de los textos otomíes del Códice de Huichapan, Artemisa Echegoyen descubrió una oración donde el autor habla en primera persona y se identifica: "na 16 junio nubuuxintonthatäbe magd[alena] m[ari] a nugui ju[an] de s[an] fran [cis]co". Ecker la había traducido así: "el 16 de junio cuando se casó Magdalena María aquí con Juan de San Francisco" (Lawrence Ecker, Códice de Huichapan, paleografía y traducción, Yolanda Lastra y Doris Bartholomew, editoras, México, Instituto de Investigaciones Antropológicas, Universidad Nacional Autónoma de México, 2001, 23). Echegoyen observó que el verbo thatä "casar", además de presentar el proclítico ton (expresando la primera persona del pretérito), lleva el sufijo dual exclusivo -be (Artemisa Echegoyen, "Códice de Huichapan, paleografia y traducción por Lawrence Ecker" [reseña], en Estudios de Cultura Otopame, Instituto de Investigaciones Antropológicas, Universidad Nacional Autónoma de México, núm. 3, 2002, 250). Una traducción más acertada de esta oración sería "El 16 de junio: entonces nos casamos Magdalena María y yo, Juan de San Francisco". Así es que Juan de San Francisco es el autor de la primera sección de este manuscrito. El descubrimiento de Echegoyen se hizo público en una presentación de la traducción de Ecker (2001) en Ixmiquilpan, hacia mediados de julio de 2001. Me enteré poco después, el 21 de julio del mismo año, cuando participé en la presentación del mismo libro en Huichapan (Doris Bartholomew y Yolanda Lastra, comunicación personal). La novedad sobre la autoría del Códice de Huichapan fue divulgada poco después (Yolanda Lastra, "Códice de Huichapan", en Códices del estado de Hidalgo/State of Hidalgo codices, Laura Elena Sotelo Santos, Víctor Manuel Ballesteros García y Evaristo Luvián Torres, coords., Pachuca, Universidad Autónoma del Estado de Hidalgo, 2001, 46). Véase también Yolanda Lastra, "El códice otomí de San Mateo Huichapan", en Arqueología Mexicana, México, Editorial Raíces, Instituto Nacional de Antropología e Historia, vol. 13, núm. 73, 2005, 34 .

${ }^{3}$ Faltan cuatro folios y con ellos los registros para los años 1445-1448, 1489-1496 y 1509-1512. El folio con los ańos 1521-1524 es un fragmento, por lo que los datos que contiene son incompletos. Cabe advertir que hay errores en el registro de buena parte de los ańos indígenas. En el cuadrete que corresponde al ańo 1425, el pintor se equivocó en el número de círculos del coeficiente numérico en la fecha 11 casa. Puso 10 casa. En el siguiente cuadrete (1426) puso 11 conejo en lugar de 12 conejo. En el registro del año 1427 corrigió este problema, apuntando correctamente la fecha 13 conejo. A partir de 1451 encontramos un problema similar, sólo que ahora a los coeficientes numéricos les sobra una unidad: dice 12 cańa en lugar de 11 caña, 13 pedernal en lugar de 12 pedernal, etcétera. No se rectifica este error hasta el siguiente año 11 caña, que corresponde al ańo europeo 1503. Así es que las fechas para un ciclo entero de 52 años presentan el error. Es 
Uno de los propósitos de este análisis fue determinar la relación entre los signos pintados, de tradición prehispánica, y las glosas alfabéticas, expresadas mediante una versión ampliada del alfabeto latino, creada por los frailes misioneros hacia mediados del siglo xvı. El Códice de Huichapan es particularmente interesante en este sentido, ya que se emplean signos muy similares a los que aparecen en los manuscritos pictóricos elaborados por nahuas, mixtecos, tlapanecos y otros grupos del Centro de México; al mismo tiempo hay glosas con una lectura de los signos pintados en lengua otomí, así como glosas más cortas en náhuatl y castellano. ${ }^{4} \mathrm{El}$ empleo simultáneo de varios lenguajes (uno visual y otros verbales) hace posible el análisis comparativo de los signos pictóricos con los lingüísticos. Los resultados nos pueden ayudar a entender cómo los otomíes empleaban el sistema de escritura desarrollado en el seno de la cultura plurilingüe del Centro de México; también nos permiten entender la naturaleza de este sistema en general.

Antes de entrar en el análisis de los signos, es necesario presentar una discusión de las categorías que se emplearán, en un primer apartado, abarcando la semasiografía, la logografía, la escritura silábica, la escritura alfabética y la escritura de rasgos fonéticos, así como los sistemas que mezclan dos a más de los tipos anteriores. No siempre hay un consenso sobre la definición de cada uno de estos términos, por lo que es conveniente precisar sus significados para los propósitos del presente estudio. En un segundo apartado se presenta una visión global de los signos pictóricos en el Códice de Huichapan, seguida por un análisis pormenorizado de los dieciséis signos para los cuales hay hipótesis sobre sus posibles asociaciones con elementos lingüísticos específicos en otomí o náhuatl.

\footnotetext{
importante tomar esto en cuenta, especialmente cuando cotejamos el contenido histórico del documento con el de otros manuscritos centromexicanos.

${ }^{4}$ Códice de Huichapan, c. 1632. Véanse: Códice de Huichapan, comentado por Alfonso Caso, facsímil del ms., estudios de Alfonso Caso y Óscar Reyes Retana, México, Telecomunicaciones de México, 1992; Códice de Huichapan, ed. digital, David Charles Wright Carr, editor, París, Editions Sup-Infor (http://www.sup-infor.com; actualización: 18 de junio de 2011; acceso: 11 de noviembre de 2011).
} 


\section{LA CLASIFICACIÓN DE LOS SIGNOS GRÁFICOS}

En este estudio aprovecho la clasificación que hace Geoffrey Sampson de los signos gráficos, basada en la unidad lingüística (o extralingüística, en el caso de los semasiogramas) representada por cada grafema (cuadro 1). Esta clasificación tiene la precisión y flexibilidad suficientes para que se aplique a cualquier sistema de escritura. Cabe mencionar que "signo", en el presente estudio, es una unidad de comunicación que expresa algo distinto a su propia esencia. "Signo gráfico" se entiende como un signo visual en un sistema de escritura. "Grafema” es una unidad significativa mínima dentro de un sistema de escritura. Los grafemas pueden combinarse en signos gráficos compuestos; en algunos casos estos signos compuestos constan de grafemas que pertenecen a categorías distintas.

Cuadro 1. Clasificación de los signos gráficos

\begin{tabular}{ll}
\hline Categoría de grafema & Estructura representada \\
\hline 1. Semasiográficos & Ideas \\
2. Glotográficos & Expresiones orales \\
2.1. Logográficos & Palabras/morfemas \\
2.2. Fonográficos & Unidades fonológicas \\
2.2.1. Silábicos & Sílabas \\
2.2.2. Alfabéticos o consonánticos & Fonemas \\
2.2.3. De rasgos fonéticos & Contrastes fonéticos \\
3. Mixtos (cualquier combinación de las categorías anteriores)
\end{tabular}

Fuente: Geoffrey Sampson, Writing systems. A linguistic introduction, Stanford, Stanford University Press, 1985, 26-45 (véase especialmente la página 32, figura 3).

\section{La semasiografia}

Los sistemas semasiográficos emplean grafemas para representar las ideas, sin que éstas estén ligadas necesariamente a las expresiones 
habladas en una lengua específica. La palabra "semasiografía" fue acuñada por Ignace Gelb en 1952, en su obra sobre la historia de la

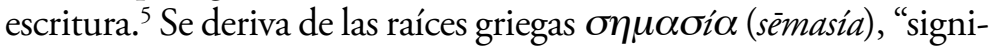
ficación", y - $\gamma \rho \alpha \varphi i \alpha$ (-graphía), "escritura". Tradicionalmente se ha usado la palabra "ideografía" para este tipo de escritura, pero esta palabra se emplea tanto para la semasiografía como para la logografía, borrando una distinción crucial entre las dos categorías. La voz "semasiografía" no aparece en la edición más reciente del diccionario de la Real Academia Espańola, ni en otros lexicones que tengo a la mano; ${ }^{6}$ algunos especialistas en el estudio de los sistemas de escritura, sin embargo, han adoptado este término. ${ }^{7}$

En el presente estudio entiendo por "escritura" los sistemas de comunicación visual, vinculados con una o más lenguas habladas, que emplean signos convencionales, plasmados en una superficie, para expresar mensajes específicos. Esta definición permite distinguir entre la escritura y las artes visuales, aunque quede borrosa la frontera entre estas dos categorías conceptuales. La semasiografía está cerca de esta frontera. Si clasificáramos algún sistema de comunicación visual como "semasiográfico", sus signos mínimos se llamarían "grafemas"; si colocáramos el mismo sistema en la categoría de "artes visuales", se podría emplear la palabra "iconema" en lugar

${ }^{5}$ Ignace J. Gelb, Historia de la escritura, Alberto Adell, traductor, Madrid, Alianza Editorial, 1976, 248; véanse también las páginas 30, 32, 38, 145, 246, 257, 322.

${ }^{6}$ Véanse las entradas que contienen sus morfemas constitutivos en las siguientes obras: Joan Corominas y José A. Pascual, Diccionario crítico etimológico castellano e hispánico, 1a. reimpresión de la 1a. ed., vol. 3, Madrid, Editorial Gredos, 1983-1985, 190; ibid., vol. 5, 197; Diccionario de la lengua española, 22a. ed. con adelantos de la 23a. ed., Madrid, Real Academia Española, 2005 (http://buscon.rae.es/diccionario/drae.htm; actualización: abril de 2005; acceso: 11 de noviembre de 2011); Guido Gómez de Silva, Breve diccionario etimológico de la lengua española, 2a. ed., México, El Colegio de México, Fondo de Cultura Económica, 1998, 327.

${ }^{7}$ Véanse: Elizabeth Hill Boone, "Introduction: Writing and recording knowledge", en Writing without words. Alternative literacies in Mesoamerica o the Andes, Elizabeth Hill Boone y Walter D. Mignolo, eds., Durham, Londres, Duke University Press, 1994, 1520; Elizabeth Hill Boone, Stories in red and black. Pictorial histories of the Aztecs and Mixtecs, Austin, University of Texas Press, 2000, 30-31; Michael D. Coe, Breaking the Maya code, Nueva York, Thames and Hudson, 1992, 289; Sampson, op. cit., 29-32. 
de "grafema" ${ }^{8}$ Para los propósitos del presente estudio, la semasiografía será considerada como un tipo de escritura. Esto nos permitirá aprovechar las herramientas teóricas desarrolladas para el análisis de la escritura, en adición a las que son propias de las artes visuales. Aquí, puesto que nuestro propósito es determinar las relaciones entre los signos y las estructuras lingüísticas, este enfoque es imprescindible.

La dicotomía "completo/incompleto" se refiere a la posibilidad de un sistema de escritura de expresar todos los elementos de un idioma. ${ }^{9}$ Estas palabras encierran una suposición implícita, pero no necesariamente válida, de que un sistema completo es más útil que un sistema incompleto. Los sistemas semasiográficos son altamente incompletos, pero este hecho no implica una limitación, ya que la comunicación se logra en un nivel translingüístico. Un sistema semasiográfico puede comunicar gran variedad de ideas, de una manera ordenada, coherente y detallada. En nuestros tiempos se están desarrollando sistemas semasiográficos, como respuesta a la globalización y la mayor movilidad de las poblaciones. Esto se puede observar en los señalamientos carreteros, las indicaciones para el lavado de la ropa, las instrucciones para la operación de los automóviles y el lenguaje gráfico de las interfaces informáticas. Todos estos sistemas utilizan signos motivados que expresan ideas, sin necesidad de expresarlas en palabras. ${ }^{10}$

\section{La logografía}

La glotografía es la escritura que expresa unidades lingüísticas (palabras, morfemas, sílabas, fonemas o rasgos fonéticos). La logografía es una división de la glotografía; expresa unidades lingüísticas con significado: palabras y morfemas. El término se deriva de las raíces griegas $\lambda{ }^{\prime} \gamma o \varsigma$ (lógos) "palabra" у - $\gamma \rho \alpha \varphi i ́ \alpha$ (-graphía), "escritura".

${ }^{8}$ Sobre el concepto de los iconemas, véase: Diana Chanquía, Lo enunciable y lo visible, México, Consejo Nacional para la Cultura y las Artes, 1998, 16.

${ }^{9}$ Sampson, op. cit., 34, 36-38.

${ }^{10}$ Ibid., 28-32.

${ }^{11}$ La palabra "logografía" aún no se encuentra en el diccionario de la Real Academia 
Etimológicamente, entonces, los logogramas serían los signos gráficos que representan palabras, aunque en la práctica usualmente expresan morfemas. No hay sistemas logográficos basados en unidades mayores (palabras o frases), porque un sistema monomorfémico es necesariamente más económico que un sistema polimorfémico, en cuanto a la cantidad de grafemas requeridos. ${ }^{12}$

La distinción entre "palabra" y "morfema" es importante en el estudio de los sistemas de escritura. Por ejemplo, la frase "sistemas logográficos", mientras consta de sólo dos palabras, contiene cinco morfemas distintos, uno de los cuales se repite: sistema, s, logo, graf, ico y $s$. El análisis detenido de estos morfemas revela que cada uno tiene un valor semántico concreto; estos valores se perderían si se intentara dividir los morfemas en unidades menores.

Hay que hacer hincapié en un aspecto esencial de la logografía, según se define en el presente estudio, porque no hay un consenso en la literatura especializada. Un ejemplo sencillo de esta situación son los intentos de clasificar la numeración arábiga moderna, que combina los grafemas /0 12345678 9/ para expresar cantidades. Para Ignace Gelb -quien considera la semasiografía como una serie de "precedentes de la escritura", dentro de un esquema evolucionista-, los numerales arábigos son logogramas. ${ }^{13}$ Gelb define el término "lo-

Española. Véanse las descripciones de sus morfemas constitutivos: Diccionario de la lengua española, op. cit.; Gómez, op. cit., 327, 421.

${ }^{12}$ Sampson, op. cit., 39. Para los fines del presente estudio, "morfema" se define según su acepción más amplia, como "elemento mínimo significativo en las palabras". Véanse las definiciones en: Coe, op. cit., 289; Diccionario de la lengua española, op. cit.; Benjamin F. Elson y Velma B. Pickett, Beginning morphology and syntax (revised), Dallas, Summer Institute of Linguistics, 1988, 2-6; Bertil Malmberg, Los nuevos caminos de la lingüistica, 20a. ed., Juan Almela, traductor, México, Siglo Veintiuno Editores, 1997, 183, 184; Nuevo diccionario enciclopédico Espasa, Madrid, Espasa Calpe, 1998, 1225. Algunas escuelas lingüísticas, sobre todo las europeas, prefieren la palabra "semantema" (Diccionario de la lengua española, op. cit.; Nuevo diccionario enciclopédico Espasa, op. cit., 1608).

${ }^{13}$ Gelb, op. cit., 33. El modelo evolucionista de Gelb ya no es sostenible. Véanse: Coe, op. cit., 25, 26; Florián Coulmas, The writing systems of the world, reimpresion, Oxford, Cambridge, Blackwell Publishers, 2003, 44-49; 158-162; Florián Coulmas, Writing systems. An introduction to their linguistic analysis, Cambridge, Cambridge University Press, 2003, 16, 196-201; Joyce Marcus, Mesoamerican writing systems. Propagan$d a$, myth, and history in four ancient civilizations, Princeton, Princeton University Press, 1992, 17-30; Wright, Los otomies, op. cit., vol. 1, 290-293. 
gografía" como "Escritura en la que un signo representa normalmente una o más palabras del idioma”. ${ }^{14}$ Aquí hay cierta confusión, porque Gelb habla de un idioma. En realidad, los numerales no representan palabras directamente; representan conceptos semánticos universales que pueden ser expresados en cualquier lengua. Karl Taube, siguiendo los pasos de Gelb, llama al grafema /3/ un logograma. Para Taube también son logogramas los 20 signos de los días en el ciclo mesoamericano de 260 días, ${ }^{15}$ a pesar de que sabemos que éstos eran leídos en varios idiomas. ${ }^{16}$ Asimismo, Ferdinand Anders, Maarten Jansen y Gabina Pérez Jiménez estiran la definición de la voz "logograma” para incluir los signos que expresan palabras con el mismo significado en varias lenguas; para ellos lo que importa "es el hecho de que su valor fonético y su valor semántico van juntos" ${ }^{17}$

Otros especialistas restringen el uso del término "logograma" a los signos que expresan morfemas en alguna lengua específica (o en el caso de la escritura china, en un conjunto de lenguas estrechamente emparentadas). Sampson pone una fórmula matemática como ejemplo de la semasiografía, haciendo hincapié en la falta de correspondencia fónica entre las lecturas de los mismos signos numéricos en diferentes idiomas. ${ }^{18}$ Michael Coe está de acuerdo con Sampson: pone la numeración arábiga moderna como ejemplo en su definición de la semasiografía. ${ }^{19}$ Puesto que los signos logográficos expresan, por definición, unidades lingüísticas con significado (morfemas o palabras), si un signo gráfico puede ser leído en dos o más lenguas que no tengan un parentesco genético cercano, es evidente que el signo no representa un morfema, sino la idea expresada

${ }^{14}$ Gelb, op. cit., 319.

${ }^{15}$ Karl Andreas Taube, “The writing system of ancient Teotihuacan”, en Ancient America (Center for Ancient American Studies), núm. 1, 2000, 3-5.

${ }^{16}$ Para los términos otomíes para estos signos, véase: Códice de Huichapan, op. cit., 6r; Códice de Huichapan, comentado por Alfonso Caso, op. cit., 11.

${ }^{17}$ Ferdinand Anders, Maarten E. R. G. N. Jansen, Gabina Aurora Pérez Jiménez, Origen e historia de los reyes mixtecos. Libro explicativo del llamado Códice vindobonensis. Codex vindobonensis mexicanus 1. Österreichische Nationalbibliothek, Viena, Madrid, Graz, México, Sociedad Estatal Quinto Centenario, Akademische Druck-und Verlagsanstalt, Fondo de Cultura Económica, 1992, 36.

${ }^{18}$ Sampson, op. cit., 30, 31.

${ }^{19}$ Coe, op. cit., 289. 
por varios morfemas equivalentes en diferentes lenguas, y tendría que ser clasificado como un semasiograma. Esta distinción, ausente en muchos estudios sobre los sistemas mesoamericanos de escritura, es de suma importancia para nuestros propósitos.

\section{La escritura silábica}

Otro tipo de glotografía, distinta a la logografía, es la fonografía. Esta última es una categoría general para clasificar los signos gráficos que expresan unidades lingüísticas de carácter fonológico. La fonografía representa sonidos puros, sin significado determinado. La variante más compleja de la fonografía es la escritura silábica.

Una sílaba puede estar constituida por una vocal (V), una consonante con una vocal (CV) o una combinación de vocales y consonantes, con distintos grados de complejidad. En la lengua castellana las sílabas más sencillas son de una vocal (por ejemplo, "a”) y las más complejas son de dos consonantes seguidas por dos vocales y una consonante final (CCVVC; por ejemplo, "cruel") ${ }^{20}$ o de dos consonantes, una vocal y dos consonantes (CCVCC; por ejemplo, "trans"). Una sílaba puede ser un elemento en un morfema ( $p a$ en "pato"), un morfema (dis en "disfuncional"), un elemento fonético en una palabra, sin respetar los límites entre los morfemas adyacentes (sas en "casas") o una palabra (“dio").

En la escritura silábica los grafemas representan sílabas. Esta clase de escritura es más económica que los sistemas logográficos, porque la cantidad de sílabas en cualquier lengua es menor a la cantidad total de los morfemas. El inventario total de grafemas se reduce, facilitando el aprendizaje del sistema. El vínculo entre los lenguajes escrito y oral se aumenta, haciendo que sea indispensable conocer la lengua del escritor para descifrar el mensaje. En la mayor parte de los sistemas silábicos el inventario de grafemas, o "silabario", se conforma de grafemas que representan las combinaciones $\mathrm{V}$ y $\mathrm{CV} .{ }^{21}$

${ }^{20}$ Morris Swadesh, El lenguaje y la vida humana, 8a. reimpresión, México, Fondo de Cultura Económica, 1995, 224.

${ }^{21}$ Coe, op. cit., 289. 


\section{La escritura alfabética}

En los sistemas alfabéticos, la mayor parte de los grafemas representan fonemas, definidos como "unidades fonológicas mínimas que en el sistema de una lengua pueden oponerse a otras en contraste significativo". ${ }^{22}$ Los contrastes semánticos entre "dato", "gato", "mato", "pato" y "rato", por ejemplo, demuestran que /d g m p r/ son fonemas distintos. En la escritura moderna del castellano, no hay una equivalencia exacta entre "letra" y "fonema". La palabra "chiquero", por ejemplo, contiene ocho letras pero sólo seis fonemas: /ch i k e r o/. Por otra parte, no son sinónimos "fonema" y "sonido". La pronunciación de un fonema puede ser afectada por su posición en una palabra y por la influencia de los fonemas vecinos; también puede variar debido a diferencias dialectales o personales. En realidad cada fonema es un conjunto de sonidos relacionados; sus variantes fónicas se llaman "alófonos". ${ }^{23}$ En comparación con los sistemas silábicos, los sistemas alfabéticos tienen un inventario grafémico reducido, ${ }^{24}$ facilitando su aprendizaje y su ejecución. Los alfabetos permiten la expresión gráfica relativamente precisa del habla.

\section{La escritura de rasgos fonéticos}

Los sistemas fonográficos que representan unidades fonológicas más específicas que el fonema se pueden clasificar como sistemas de rasgos fonéticos. En estos sistemas los grafemas representan contrastes fónicos. La escritura de rasgos va más allá del nivel fonémico, alcanzando el nivel puramente fónico; es capaz de registrar contrastes fónicos, aunque éstos no afecten el significado de los morfemas; es

${ }^{22}$ Diccionario de la lengua española, op. cit.

${ }^{23}$ Ibid.; Jeffrey C. Hahner, Martin A. Sokoloff y Sandra L. Salisch, Speaking clearly. Improving voice and diction, 5a. ed., Boston, Burr Ridge, Dubuque, Madison, Nueva York, San Francisco, St. Louis, McGraw-Hill, 1997, 42; Swadesh, op. cit., 216-220.

${ }^{24}$ Los silabarios típicamente tienen entre 40 y 90 grafemas, mientras lo alfabetos suelen tener entre 20 y 35 (Coe, op. cit., 43). Para una exposición de la relación entre economía y precisión de varios silabarios antiguos, véase: Coulmas, Writing systems, op. cit., 81-87. 
decir, permite el registro de los alófonos. Los lingüistas modernos han desarrollado varios sistemas de escritura de rasgos fonéticos, como el alfabeto fonético internacional, ${ }^{25}$ la taquigrafía fonética de Isaac Pitman y los cuadros de rasgos fonéticos de Noam Chomsky y Morris Halle. ${ }^{26}$ Estos sistemas registran la posición de la lengua, el grado de apertura de la boca y la vocalidad o nasalidad, en el caso de los rasgos vocales, y gran variedad de rasgos consonánticos, tomando en cuenta la sonoridad o insonoridad, así como el lugar y el método de articulación. ${ }^{27}$ Un ejemplo más añejo de la escritura de rasgos fonéticos es el sistema hangul de Corea. Fue inventado, según la tradición, por el rey Sejong, con la asesoría de un equipo de sabios, entre 1441 y 1450 d.C. ${ }^{28}$

\section{Sistemas mixtos}

Varios sistemas de escritura son difíciles o imposibles de colocar en alguna de las categorías definidas hasta aquí, porque combinan signos de dos o tres categorías (semasiografía, logografía y fonografía). En el sistema cuneiforme de los sumerios, por ejemplo, se combinan semasiogramas, logogramas y fonogramas silábicos. Un procedimiento frecuente es la asociación de signos logográficos primarios con semasiogramas secundarios llamados "determinativos semánticos"; éstos relacionan los logogramas con campos semánticos específicos para determinar la lectura correcta de un logograma que de otra manera sería ambiguo. De manera similar hay logogramas primarios que se combinan con fonogramas silábicos secundarios, para indicar la pronunciación correcta del logograma; los signos silábicos se llaman "complementos fonéticos". También se emplea el principio de la homofonía, en el cual un logograma se emplea para dos palabras con sonido idéntico (o casi idéntico) pero con distinto

${ }^{25}$ Ibid., 103-105; "The international phonetic alphabet”, op. cit., 2005.

${ }^{26}$ Sampson, op. cit., 40-42.

${ }^{27}$ Hahner, Sokoloff y Salisch, op. cit., 29, 45-47.

${ }^{28}$ Coulmas, The writing systems of the world, op. cit., 118-122; Coulmas, Writing systems, op. cit., 156-165; Sampson, op. cit., 120-144; "Writing” en Encyclopedia Britannica CD 99, edición digital, Chicago, Encyclopædia Britannica, 1998. 
significado. ${ }^{29}$ La escritura egipcia antigua emplea los mismos principios fundamentales que el cuneiforme sumerio. Hay semasiogramas, logogramas y fonogramas; estos últimos sólo representan consonantes, no vocales, y pueden ser monoconsonánticos, biconsonánticos o triconsonánticos. Asimismo hay determinativos semánticos, complementos fonéticos y logogramas que emplean juegos de homofonía. ${ }^{30}$

Los sistemas de escritura de la antigua Mesoamérica también fueron mixtos. De ellos, el sistema mejor conocido es el de los mayas del periodo Clásico. Coe lo clasifica como un sistema logográfico, pero tiene que estirar la definición de esta categoría para dar cabida a la escritura maya: "logographic script [:] A mixed writing system consisting of logograms and phonetic signs, or semantic signs compounded with phonetic signs" ${ }^{31}$ Evidentemente la escritura maya sería clasificada como un sistema mixto, no logográfico, dentro del esquema usado en el presente estudio. Los grafemas mayas (que pueden poseer diversos grados de motivación o arbitrariedad) son semasiográficos, logográficos y silábicos. Estos grafemas se combinan en bloques, dispuestos en cuadrículas, hileras o columnas. Dentro de un bloque puede haber uno o varios grafemas, representando una o más palabras. Con frecuencia se combinan grafemas de distintas categorías para escribir una sola palabra. Son comunes los complementos fonéticos, o afijos silábicos, agregados al signo principal. Son menos frecuentes los determinativos semánticos, o afijos semasiográficos que ayudan a determinar el significado de algún

${ }^{29}$ Coulmas, The writing systems of the world, op. cit., 76-79; Coulmas, Writing systems, op. cit., 46-49; M. W. Green, "Early cuneiform", en The origins of writing, Wayne M. Senner, editor, reimpresión de la 1a. ed., Lincoln, Londres, University of Nebraska Press, 1991, 43-57; Sampson, op. cit., 46-56.

${ }^{30}$ Carol Andrews, The Rosetta Stone, 20a. reimpresión, Londres, British Museum Press, 1998, 29; Mark Collier y Bill Manley, How to read Egyptian hieroglyphs. A step-bystep guide to teach yourself, Londres, British Museum Press, 1998; Coulmas, The writing systems of the world, op. cit., 57-71; Coulmas, Writing systems, op. cit., 170-176; Henry George Fischer, "The origin of Egyptian hieroglyphs", en The origins of writing, Wayne M. Senner, editor, reimpresión de la 1a. ed., Lincoln, Londres, University of Nebraska Press, 1991, 59-76.

${ }^{31}$ Coe, op. cit., 289. 
signo gráfico. En ocasiones se usa el principio de la homofonía. ${ }^{32} \mathrm{De}$ esta manera la escritura maya es similar a los sistemas de los antiguos sumerios y egipcios.

\section{ANÁlisis de los SigNos gRÁficos EN EL CÓDICE DE HUICHAPAN}

Aquí señalo algunas de las características del conjunto de los signos gráficos pintados en el Códice de Huichapan. Para facilitar esta tarea, elaboré una base de datos con el software Access de Microsoft Office. A continuación presento los resultados de este estudio, resaltando la distribución de los signos por categoría temática, por su ubicación en la gradación entre la motivación y la arbitrariedad, y por su naturaleza semasiográfica o glotográfica.

En la base de datos de los signos gráficos del Códice de Huichapan hay 610 registros. Cada uno corresponde a un grafema o un signo compuesto. ${ }^{33}$ En el cuadro 2 se señala la cantidad de registros que pertenecen a cada una de las 17 categorías, definidas con base en el contenido de los signos.

${ }^{32}$ Michael D. Coe y Mark Van Stone, Reading the Maya glyphs, Londres, Nueva York, Thames and Hudson, 2001; John F. Harris y Stephen K. Stearns, Understanding Maya inscriptions, Filadelfia, The University Museum of Archaeology and Anthropology, University of Pennsylvania, 1992, 5-10; Floyd G. Lounsbury, "The ancient writing of Middle America”, en The origins of writing, Wayne M. Senner, editor, reimpresión de la 1a. ed., Lincoln, Londres, University of Nebraska Press, 1991, 203-237; Linda Schele, "Introduction to reading Maya hieroglyphs", en Notebook for the XXVth Maya Hieroglyphic Forum at Texas, edición xerográfica, Austin, Maya Workshop Foundation, 2001, 1a. parte, 1-75.

${ }^{33}$ Cuando aislé los signos gráficos para su captura en la base de datos, tuve que establecer un criterio adecuado para su división. La mayor parte de los signos son compuestos, con dos o más grafemas. Después de hacer algunas pruebas, entendí que si registraba cada grafema por separado, los signos compuestos se atomizaban a tal grado que se perdían los significados. En el otro extremo, si registraba las agrupaciones más complejas como unidades, la base de datos perdía funcionalidad. Opté por considerar como unidades los signos toponímicos, antroponímicos, calendáricos, etcétera, sean grafemas o signos compuestos. Los signos antropomorfos, por ejemplo, incluyen todas las partes del cuerpo de la persona representada, incluyendo sus peinados e indumentaria, mas no los objetos culturales que cargan. Las fechas se tratan como unidades, incluyendo el signo del día y el coeficiente numérico. Para no perder la posibilidad de identificar y reunir los grafemas individuales que conforman cada signo compuesto, éstos se registran en cada formulario en el campo "significado", mediante el uso de palabras claves. 
Cuadro 2. Clasificación por significado de los signos gráficos en el Códice de Huichapan

\begin{tabular}{lcc}
\hline Categoría & Cantidad de signos & Porcentaje \\
\hline Antropomorfos & 123 & 20.16 \\
Culturales & 122 & 20.00 \\
Calendáricos & 113 & 18.52 \\
Antroponímicos & 73 & 11.97 \\
Toponímicos & 64 & 10.49 \\
Metafóricos & 45 & 7.38 \\
Arquitectónicos & 23 & 3.77 \\
No clasificados & 16 & 2.62 \\
Numéricos & 8 & 1.31 \\
Gentilicios & 7 & 1.15 \\
Zoomorfos & 6 & 0.98 \\
Geográficos & 4 & 0.66 \\
Mixtos & 3 & 0.49 \\
Fitomorfos & 2 & 0.33 \\
Astrales & 1 & 0.16 \\
Total: 610 signos & & \\
\hline
\end{tabular}

Las categorías con la mayor cantidad de registros son los signos antropomorfos y culturales, cada una con cerca de $20 \%$ del total. Esto es comprensible, ya que se trata de un documento histórico, que registra los hechos notables de los seńores. Los signos antropomorfos son las representaciones de estos señores y de otras personas. Los signos culturales representan las cosas hechas por manos humanas; la mayor parte son asientos señoriales (53 casos), escudos (18 casos) y macanas (15 casos, sin contar una macana con plumas para el sacrificio gladiatorio). La siguiente categoría, por la cantidad de registros, 
es la de los signos calendáricos, con un poco menos de 19\% del total. Esto se explica por la estructura de la sección de los anales pictóricos, con una banda de signos anuales que corre al pie de las páginas. Tenemos una buena cosecha de signos antroponímicos (más de 12\% del corpus) y toponímicos (más de 10\%), como sería de esperar, considerando la temática. Los signos metafóricos representan más de 7\% de los signos; la mayor parte de éstos se relaciona con la guerra y la conquista: humo y llamas, flechas y escudos. Las demás categorías tienen menos de 5\% cada una: los signos arquitectónicos, no clasificados, numéricos, gentilicios, zoomorfos, geográficos, mixtos, fitomorfos y astrales.

En cuanto al grado de motivación de estos signos, el análisis hecho por medio de la base de datos arrojó los resultados que se expresan en el cuadro 3 .

Cuadro 3. La motivación de los signos gráficos en el Códice de Huichapan

\begin{tabular}{lcc}
\hline Categoria & Cantidad de signos & Porcentaje \\
\hline Motivados & 555 & 90.98 \\
Intermedios & 26 & 4.26 \\
Sin determinar & 21 & 3.44 \\
Arbitrarios & 8 & 1.31 \\
Total: 610 signos & & \\
\hline
\end{tabular}

La mayoría de los signos pintados en este manuscrito, casi $91 \%$, son motivados. Clasifiqué como intermedios a más de $4 \%$, porque el alto grado de estilización dificulta su identificación. El menor grado de motivación de algunos de estos signos probablemente se debe a que parte del Códice de Huichapan parece ser una copia de un documento anterior, y que fue pintada durante la primera mitad del siglo XVII, cuando la tradición gráfica centromexicana se estaba olvidando. Es probable que el autor del manuscrito no comprendiera el significado de algunos de los grafemas que estaba copiando. Los 
únicos signos que clasifiqué como arbitrarios, por no tener una relación aparente con algún objeto real, son las vírgulas de la palabra que aparecen 8 veces en este manuscrito, en grupos de 1, 2, 3 o 5 volutas; constituyen más de $1 \%$ del total. Más de $3 \%$ recibieron la clasificación "sin determinar". Algunos están en esta categoría por su alto grado de deterioro. Otros no se pudieron identificar, lo cual sugiere cierto grado de arbitrariedad, aunque sin identificar sus significados no fue posible evaluar su relación visual con las cosas representadas.

Para determinar la naturaleza semasiográfica o glotográfica de cada uno de los 610 signos en el Códice de Huichapan, apliqué las cinco reglas que desarrollé para este propósito:

- si el signo puede ser leído en dos o más lenguas (que no tengan una relación genética cercana) es un semasiograma;

- si el signo presenta algún elemento que sólo tiene sentido en una lengua específica, o un conjunto de lenguas estrechamente emparentadas (como en el caso del uso del principio de la homofonía, en el cual un signo gráfico expresa una palabra, un morfema, una sílaba o un fonema mediante la representación de una cosa asociada con un morfema homófono o cuasihomófono), es glotográfico. Un signo glotográfico puede ser logográfico o fonográfico, dependiendo de la estructura lingüística representada: si ésta es una palabra o un morfema, se trata de un logograma; si es una sílaba o un fonema, es un fonograma;

- hay que tomar en cuenta que los signos gráficos compuestos pueden incluir grafemas de distintos tipos; un logograma compuesto, por ejemplo, puede contener un semasiograma y un fonograma;

- si hay buenas razones para sospechar que un signo tenga un valor fonético, pero no hay suficiente seguridad para afirmarlo sin reservas (por ejemplo, cuando hay dudas en cuanto a la relación del signo con una palabra, o acerca de la etimología o significado de la palabra), hay que dejar el signo sin clasificar;

- si no es posible identificar la cosa que quiso representar el autor, o en su defecto el significado del signo, tampoco se puede clasificar el signo. 
La presencia en este manuscrito de glosas en otomí, náhuatl o castellano permite profundizar en las relaciones entre los signos pintados y los elementos lingüísticos (cuadro 4).

CuAdro 4. La frecuencia de los semasiogramas y los glotogramas en el Códice de Huichapan.

\begin{tabular}{lcc}
\hline Categoria & Cantidad de signos & Porcentaje \\
\hline Semasiogramas & 566 & 92.79 \\
Sin determinar & 44 & 7.21 \\
Glotogramas & 0 & 0.00 \\
Total: 610 signos & & \\
\hline
\end{tabular}

Los resultados de este análisis muestran una escasa relación de los signos pintados con las estructuras lingüísticas, pues no se detectó ningún signo claramente glotográfico, y los casos dudosos representan sólo alrededor de $7 \%$ del total.

De los 44 signos gráficos asignados a la categoría "sin determinar", en 28 casos esta situación se debe a la imposibilidad de identificar el signo o de determinar su papel semántico dentro de su contexto gráfico inmediato. En estos casos, estamos obligados a dejar los signos sin clasificar. No hay razones concretas para sospechar que estos 28 signos tengan valores glotográficos; simplemente carecemos de información suficiente para clasificarlos. Para los 16 signos restantes, tengo algunas hipótesis sobre sus vínculos con elementos lingüísticos específicos, en otomí o náhuatl, aunque en todos los casos tengo dudas al respecto. De estos 16 signos, 8 son toponímicos, 3 son antroponímicos, 3 son numéricos y 2 quedaron sin clasificar en cuanto a su contenido.

Antes de proceder al análisis de los signos, cabe aclarar que algunas de mis hipótesis sobre los posibles valores glotográficos son más probables que otras. Si bien he optado por registrar aquí todas las posibilidades, como muestra de la aplicación del método que estoy empleando, hay que reconocer que las explicaciones más complejas son las que con menos probabilidad estaban en la mente de los anti- 
guos escribanos-pintores indígenas. Este principio se puede llamar la "ley de la parsimonia" y es conocida también como la "ley de la economía" o "la navaja de Ockham". ${ }^{34}$

El primero de nuestra lista de posibles glotogramas se registra en la base de datos con la clave hui05v_06. ${ }^{35}$ Su aspecto es poco común en los manuscritos pintados del Centro de México: una masa de bandas torcidas, que tal vez representa una piedra. Se encuentra en la nómina de pueblos que ocupa ambos lados del folio 5, por lo que sabemos que se trata de un signo toponímico. ${ }^{36}$ La glosa alfabética relacionada con el signo toponímico dice, en otomí, "Antomeni". Propongo dos etimologías alternativas; la primera implica la restitu-

${ }^{34}$ Esta regla proviene de la filosofía escolástica y ha sido usada desde el siglo xIv d.C. por Durand de Saint-Pourçain (circa 1270-1334) y William of Ockham (circa 12851349) (Frederick Copleston, A history of philosophy. Volume III. Late mediaeval and renaissance philosophy. Part I. Ockham to the speculative mystics, Garden City, Image Books, 1963, 56-133; Paul D.Vignaux, "Ockham, William of", en Encyclopedia Britannica CD 99, edición digital, Chicago, Encyclopædia Britannica, 1998). Desde entonces ha sido aprovechada por muchos científicos. La navaja de Ockham se resume en la oración latina Non sunt multiplicanda entia preter necessitatem: "las entidades no se multiplican más allá de lo necesario" (H. Russell Bernard, Social research methods. Qualitative and quantitative approaches, Thousand Oaks, Londres, New Delhi, Sage Publications, 2000, 52, 287). Dicho de otra manera, cuando dos hipótesis parecen explicar adecuadamente la evidencia, la más sencilla probablemente es la correcta (Karl Raimund Popper, Conjectures and refutations. The growth of scientific knowledge, reimpresión de la 5a. ed., Londres y Nueva York, Routledge, 2000, 108, 171).

${ }^{35}$ Las imágenes de los signos mencionados en el texto con su clave alfanumérica se encuentran en el apéndice del presente texto. Para información más detallada, véase: Wright, Los otomies, op. cit., vol. 2, 514-640. Las letras "hui” indican que el signo es del Códice de Huichapan. El número " 05 " se refiere al folio y la letra "v" señala que el signo está en el lado verso del folio. El número "06” al final es el número consecutivo del signo dentro de la página, buscando una aproximación al orden de lectura original.

${ }^{36}$ Una búsqueda de signos parecidos en 124 manuscritos centromexicanos produjo una cosecha bastante parca. Los signos más similares son las piedras del hogar (The Codex Mendoza, facsímil del ms., vol. 3, Frances F. Berdan y Patricia Rieff Anawalt, editoras, Berkeley, Los Ángeles, Oxford, University of California Press, 1992, 8r, 60r); una bola de volutas de color gris (ibid., 37r; Códice Moctezuma o Matrícula de tributos, facsímil del ms., Luis Reyes García, editor, Graz, México, Akademische Druck-und Verlagsanstalt, Fondo de Cultura Económica, 1997, 9r); y una prenda textil en proceso de lavado sobre una piedra (The Codex Mendoza, op. cit., 50r; Códice Moctezuma, op. cit., 14v). Los que tienen una mayor probabilidad de relacionarse con el signo hui05v_06 del Códice de Huichapan, tomando en cuenta la glosa que lo acompańa, son las piedras del hogar y la tela lavada. 
ción de la nasalización en la tercera sílaba: (1) Antomëni, "la piedra de los parientes"; y (2) Antomeni, "la piedra de lavar". ${ }^{37}$ Cualquiera de las dos lecturas se puede relacionar con el signo pintado. Asimismo cabe la posibilidad de que el escritor-pintor hubiera aprovechado en este signo el juego cuasihomófono entre los morfemas mëni, "pariente" y meni, "lavar", expresando uno con la representación del otro. Por estas razones, este signo toponímico debe quedar en la lista de los posibles glotogramas, como hipótesis, hasta encontrar evidencia refutante que nos obligue a quitarlo.

Otro posible glotograma tiene la clave hui22r_07 en la base de datos; es el conocido grafema centromexicano del cerro, con un chorro de agua saliendo de su base y un insecto volátil en la cima. Una de las glosas asociadas es Ant'axt'oho, que significa "el cerro blanco" en otomí, atendiendo a la forma de la glosa. ${ }^{38} \mathrm{La}$ falta de correspondencia entre la glosa alfabética y el signo pintado, sin embargo, nos insta a buscar una hipótesis alternativa. Si nasalizamos la vocal de la segunda sílaba de la glosa, obtenemos Ant'äxt’ọho, "el cerro de la(s) langosta(s)", topónimo que evidentemente tiene una mayor relación con el signo pintado. ${ }^{39}$ Es probable que la falta del signo diacrítico para la nasalización se deba a un descuido del autor del Códice de Huichapan. La existencia de dos palabras con una sutil distinción fonológica, sin embargo, abre la posibilidad de que se

${ }^{37}$ Los análisis morfológicos de las voces otomíes, en este caso y en los demás que se mencionan en el presente trabajo, se encuentran en el apéndice 2 del presente artículo.

${ }^{38}$ Soustelle apunta el nombre otomí del Nevado de Toluca: t’axt’’oho, "cerro blanco" (Jacques Soustelle, "Deux contes otomis", en Journal de la Société des Américanistes, serie nueva, vol. 27, 1935, 2). Wallis registra un lugar llamado Cerro Blanco, T'axt'óho en otomí, en el municipio de Ixmiquilpan, Hgo. (Ethel Emilia Wallis, "Toponimia otomí del valle del Mezquital", en Revista Mexicana de Estudios Antropológicos [Sociedad Mexicana de Antropología], vol. 14, 1a. parte, 1956, 154). Ecker apunta otro lugar con el mismo nombre en Santiago de Anaya (Lawrence Ecker, "Compendio de gramática otomí (introducción a un diccionario otomí-español)", en Anales del Instituto Nacional de Antropología e Historia, época 6, vol. 4, 1952, 167).

${ }^{39}$ Urbano (op. cit., 260r) registra la voz tä̈xi, "Langosta de la tierra", misma que hace equivalente de la palabra náhuatl chapolin. López Yepes proporciona la palabra compuesta täxt’oho, "Chapultepec". La voz náhuatl Chapoltepec significa "en el cerro de la[s] langosta[s]" (Joaquín López Yepes, Catecismo y declaración de la doctrina cristiana en lengua otomí, con un vocabulario del mismo idioma, México, Oficina del Ciudadano Alejandro Valdés, 1826, 134). 
haya aprovechado el juego cuasihomófono entre t'axi ("blanco") y täxi ("langosta") para representar "el cerro blanco" con una pintura de un cerro con una langosta. Contra esta posibilidad está el hecho de que hubiera sido mucho más fácil dejar la cima del cerro sin pigmento que pintar una langosta. Aún así, merece un lugar en nuestra mesa de discusión, como hipótesis de trabajo, con el fin de considerar todas las opciones.

El tercer signo que podría ser un glotograma está registrado con la clave hui25r_02, y consta del signo del cerro con tinta negra en su parte superior. Se asocia con una glosa que contiene el topónimo otomí An'bot’ộho. Asimismo hay otro signo de un cerro que carece del color negro (hui31r_11), aunque en la glosa correspondiente aparece el mismo topónimo otomí, An'botóoho. Es posible que haya una relación directa entre estos signos y el señorío otomí que los nahuas llamaban Tliliuhquitepec, "en el cerro negro", en el límite noroccidental del territorio dominado por la confederación tlaxcalteca, cerca de la frontera con el Acolhuacan, el dominio de los señores de Tetzcoco. ${ }^{40}$ El topónimo otomí mencionado, An’bot’ọoho, tiene dos posibles significados: "el cerro negro" y "donde abundan los cerros". Esto se debe a la sílaba 'bo, que significa "negro" o "donde abunda[n]". La existencia de dos traducciones alternativas de An'botóoho, ambos al ser factibles en los contextos donde se encuentran los signos pintados, me obliga a seguir considerando la posibilidad de una lectura glotográfica, donde la bivalencia de la sílaba 'bo se aprovecha para representar la idea "donde abundan los cerros" mediante la aplicación de la tinta negra al grafema del cerro. Pero lo más probable es

${ }^{40}$ Sobre Tliliuhquitépec, véase: Claude Nigel Byam Davies, Los señoríos independientes del imperio azteca, México, Instituto Nacional de Antropología e Historia, 1968, 66150. Wallis ofrece una alternativa más: el pueblo llamado 'Bot'ôho, o Cerro Prieto, en el municipio de Alfajayucan, en la parte norcentral del Mezquital (Wallis, op. cit., 154). El diccionario del otomí del Mezquital registra la misma palabra como término geográfico genérico: “'bot'oho [...] s[ustantivo] cerro prieto 'Ra ya t'oho t'embi ra 'bo'tho, nge'ä xá mboi ra hai o ya do o njabu thu'mbabi. A unos cerros le dicen cerro prieto, porque está prieta la tierra o las piedras. Variantes 'bo'tho, 'botho [...]" (Luis Hernández Cruz, Moisés Victoria Torquemada, Donald Sinclair Crawford, Diccionario del hñ̈hñu [otomí] del Valle del Mezquital, estado de Hidalgo, 2a. reimpresión, México, Instituto Lingüístico de Verano, 2004, 28). 
que la palabra An'botóho signifique "el cerro negro" y que sea el equivalente semántico de Tliliuhquitepec. En este caso los signos mencionados del Códice de Huichapan serían semasiogramas.

Los demás signos toponímicos con posibles lecturas glotográficas son signos compuestos que combinan el grafema del cerro con el grafema de la bandera. Los signos hui32r_02 y hui32v_16 tienen ambos grafemas, sin elementos adicionales. El signo hui29v_11 presenta el cerro, la bandera y un ave de plumaje gris y pico largo. El signo hui30r_03 tiene el cerro con la bandera; en el interior del cerro hay un grafema que representa la cabeza de un hombre con una gran perforación en la nariz. Algunos de estos signos se asocian con glosas alfabéticas:

- hui32r_02 (cerro + bandera); sin glosa que se relacione con el signo.

- hui32v_16 (cerro + bandera); sin glosa que se relacione con el signo.

- hui29v_11 (cerro + bandera + ave gris); topónimo en glosa relacionada: Amábexte Antọoho, "lugar de banderas, el cerro" en otomí.

- hui30r_03 (cerro + bandera + cabeza humana con nariz perforada + mechón de pelo [?]); topónimos en glosas relacionadas: (1) Amábex [te Ant'óho], "lugar de banderas, el cerro" en otomí (topónimo reconstruido con base en la glosa anterior); (2) Zopantepec, "en el cerro de la bandera de tela/en el cerro del lugar de tela" en náhuatl; otra lectura de la misma glosa es Tzompantepec, "en el cerro de la bandera de pelo" (tzompantli también significa "colorín" y "altar de cráneos", dependiendo de la duración de la vocal en la segunda sílaba, por lo que Tzompantepec podría traducirse también "en el cerro de los colorines" y "en el cerro del altar de cráneos"). Algunos de estos contrastes significativos dependen de la duración vocálica de la sílaba pan, la cual no se indica en el manuscrito. ${ }^{41}$

${ }^{41}$ Para el análisis morfémico de esta voz náhuatl y las demás que aparecen en el presente artículo, véase: David Charles Wright Carr, Lectura del nábuatl. Fundamentos para la traducción de los textos en náhuatl del periodo Novohispano Temprano, México, Instituto Nacional de Lenguas Indígenas, 2007, 225-232. Para escribir las palabras en náhuatl uso cursivas para la ortografía tradicional, la cual no registra los contrastes en duración vocá- 
Es probable que estos signos, por lo menos algunos de ellos, representen el señorío llamado en náhuatl Pantepec, localizado en la Sierra Madre Oriental, en una región donde convivían huastecos, totonacas, tepehuas, otomíes y nahuas. ${ }^{42}$ Según el Libro de las tasaciones, de mediados del siglo XvI, Pantépec (llamado en esta fuente "Tepantepeque") se encontraba "en la Guasteca, camino de Pánuco". ${ }^{43}$ Fue conquistado por el señor tenochca Moteuczoma Xocoyotzin, quien ascendió al poder en 1502. Los registros mencionados del Códice de Huichapan corresponden a los ańos 1504, 1506, 1517 y $1519 / 1520$, por lo que caen dentro del reinado de este señor. ${ }^{44} \mathrm{El}$ topónimo otomí Ama'bexte Ant’óho ("lugar de banderas, el cerro") es una lectura semasiográfica de los signos pintados. Su equivalente náhuatl, Pantepec, puede traducirse como "en el cerro de las banderas". ${ }^{45}$ No tengo hipótesis alguna para explicar la presencia del grafema del ave gris, pero el grafema de la cabeza con la nariz perforada funciona en otros contextos -en el Códice de Huichapan y en otros manuscritos pintados- como un signo gentilicio con el significado "huasteco". ${ }^{6}$ Puesto que Pantépec se encuentra en la región huasteca, este signo también parece tener un valor semasiográfico. Hasta aquí todo apoya la clasificación de estos signos toponímicos como

lica ni los saltillos (oclusivas glotales). Las palabras entre líneas verticales están escritas con una ortografía "tradicional fonémica", desarrollada por J. Richard Andrews y aprovechada por Frances Karttunen y John Bierhorst, que marca las vocales largas con rayitas horizontales sobre las letras y expresa los saltillos con la letra $h$. Pongo las versiones en el alfabeto fonético internacional entre barras. Sobre la fonología del náhuatl y las ortografías mencionadas, véase: Wright, Lectura del náhuatl, op. cit., 46-75.

${ }^{42}$ Sobre Pantepec, su ubicación y su historia prehispánica, véase: Michael Ernest Smith y Frances F. Berdan, "Province descriptions", en Aztec imperial strategies, Washington, Dumbarton Oaks, 1996, 291.

${ }^{43}$ El libro de las tasaciones de pueblos de la Nueva España. Siglo XVI, Francisco González de Cossío, editor, México, Archivo General de la Nación, 1952, 76.

${ }^{44}$ La conquista de Pantepec por Moteuczoma Xocoyotzin se registra en el folio 16r del Códice mendocino (The Codex Mendoza, op. cit.) y probablemente en el folio 29v (año 1504) del Códice de Huichapan (op. cit.)

${ }^{45}$ En un vocabulario de principios del periodo Independiente se registra este topóni-

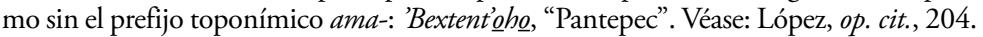

${ }^{46}$ Sobre la gran perforación nasal como signo gentilicio relacionado con los huastecos, véase: Guy Stresser-Péan, El Códice de Xicotepec. Estudio e interpretación, Puebla, México, Gobierno del Estado de Puebla, Centre d'Etudes Mexicaines et Centraméricaines, Fondo de Cultura Económica, 1995, 91. 
semasiogramas. Lo que abre la posibilidad de una lectura glotográfico de algunos de los grafemas en este conjunto de signos es la presencia de la glosa náhuatl Zopantepec, con todos los posibles significados mencionados. La silaba $z o$, que significa "tela" o "sangrarse", es problemática, ya que no encuentro el topónimo Zopantepec en otras fuentes. Pero la polivalencia del topónimo náhuatl abre la posibilidad de una serie de juegos homófonos o cuasihomófonos, especialmente cuando admitimos la hipótesis de que el autor de la glosa haya querido expresar la palabra Tzompantepec. ${ }^{47}$ El escritor nahua que pintó el Códice mendocino empleó varios juegos de este tipo en la escritura de los topónimos Tzompahuacan, Tzompanco y Papantla; todos estos signos compuestos incluyen los grafemas para "bandera" (pantli), y dos de ellos presentan el signo para "pelo" (tzontli). En el primer caso, una bandera de pelo (tzompantli) se representa encima de un altar de cráneos (tzompantli). ${ }^{48}$ Hay un grafema (hui30r_07) que representa un mechón de pelo, junto al signo hui30r_03, el cerro con la bandera y la cabeza del huasteco. No sé si tiene el valor semántico "pelo", relacionándose con este signo toponímico, o si tiene el valor “400”, vinculándose con el bulto mortuorio que se encuentra a su lado, ya que se encuentra entre ambos signos. ${ }^{49}$ En el primer caso, se reforzaría la hipótesis de una lectura glotográfica en náhuatl del signo toponímico. A pesar de estas consideraciones, veo más probable la interpretación semasiográfica de estas representaciones de cerros con banderas, pero por las diversas posibilidades de lecturas glotográficas en náhuatl, estos signos merecen un lugar en la lista de posibles glotogramas, ya que no hay razones de peso para eliminarlos.

${ }^{47}$ En los documentos del periodo Novohispano Temprano es usual encontrar la sílaba tzon escrito "çon" o "çun"; véanse, por ejemplo, las glosas en el Códice mendocino (The Codex Mendoza, op. cit., 24v, 35r). Puede haber variaciones aún mayores en los textos en náhuatl escritos por hablantes del otomí como primera lengua, como lo fue el autor de las glosas del Códice de Huichapan.

${ }_{48}$ The Codex Mendoza, op. cit., 24v, 35r, 52r. Sobre la asimilación fonética /n/ +/p/ $>/ \mathrm{mp}$ /, véase: J. Richard Andrews, Introduction to classical Nahuatl. Revised edition, Norman, University of Oklahoma Press, 2003, 35; Wright, Lectura del náhuatl, op. cit., 68.

${ }^{49}$ La naturaleza semasiográfica o glotográfica del signo del mechón de pelo se discute más adelante. 
Ahora hablaré de los tres signos antroponímicos que tienen posibles valores glotográficos. El primero es el signo hui13v_07. Se trata de un signo compuesto con dos grafemas: uno representa una mazorca de maíz, el otro la cabeza de un águila. Este signo se une a la cabeza de la representación de una mujer indígena para indicar que se trata de un signo antroponímico. El nombre otomí que aparece en el texto asociado con este conjunto de signos pictóricos es Egaxuntäxi, "mazorca tierna del águila”. La correspondencia entre este antropónimo otomí y el signo pintado parece indicar que éste sea un semasiograma. Sin embargo, el escritor colocó una glosa alfabética en náhuatl junto al signo: “quauhxilotl”. Esta voz es polisémica; puede ser analizado de dos maneras. Una interpretación corresponde exactamente con el significado del antropónimo otomí, "mazorca tierna del águila"; así la primera sílaba, cuauh (cuāuh / $\mathrm{k}^{\mathrm{w}} \mathrm{a}: \mathrm{w} /$ ), sería la raíz del sustantivo cuauhtli (cuāuhtli), "águila”, y las dos sílabas siguientes expresarían la forma absolutiva de la palabra xilotl (xīlōtl), "mazorca tierna”. La segunda posibilidad en náhuatl sería que la primera sílaba sea la raíz del sustantivo cuahuitl (cuahuitl), "palo/árbol/bosque". ${ }^{50}$ Según las reglas de la composición y de los cambios morfofonémicos en el náhuatl novohispano del Centro de México, después de quitar el sufijo sustantivo $-t l$ de esta palabra para anteponer su raíz a otro sustantivo, el fonema $i$ también se pierde, quedando la sílaba cuauh (cuauh $/ \mathrm{k}^{\mathrm{w}} \mathrm{aw} /$ ). El segundo elemento de este sustantivo compuesto sería el mismo que identificamos en la primera interpretación: xilotl (xīlōtl), "mazorca tierna". Así la palabra cuauhxilotl cuauhxīlōtl significaría literalmente "la mazorca tierna del palo/árbol/bosque”, por ser el nombre de un árbol tropical (el cuajilote, Parmentiera edulis) y de su fruta. ${ }^{51}$ La dis-

${ }^{50}$ Ambos vocablos se pueden encontrar con $c u$ o qu en la posición inicial, de acuerdo con las convenciones ortográficas del periodo Novohispano Temprano; delante de la vocal $a$ representan la consonante cu $\left(/ \mathrm{k}^{\mathrm{w}} /\right)$. Véase: Wright, Lectura del nábuatl, op. cit., 46-56.

${ }^{51}$ Karttunen registra la palabra cuauhxīlōtl, compuesta de las raíces cuahuitl y xīlōtl, en los vocabularios modernos de Tetelcingo, Zacapoaxtla y Xalitla, usada para identificar un árbol tropical (Parmentiera edulis) y su fruta (Frances Karttunen, An analytical dictionary of Nahuatl, 2a. ed., Norman, University of Oklahoma Press, 1992, 66). Santamaría registra esta especie bajo la voz castellana cuajilote. Véase: Francisco J. Santamaría, Diccio- 
tinción fonética entre estas dos alternativas hipotéticas es sutil: la primera (cuāuhxīlōtl) tiene una a larga (ā) en la primera sílaba, mientras la segunda (cuauhxīlōtl) tiene la $a$ corta (a). Ahora bien, si el escritor-pintor estaba pensando en el significado "mazorca tierna del águila" cuando pintó la mazorca y la cabeza de águila, este signo sería un semasiograma. Si estaba pensando en el árbol o la fruta mencionados, se trataría de un juego cuasihomófono, aprovechando la cabeza del águila $/ \mathrm{k}^{\mathrm{w} a ̄ w} /$ para comunicar la idea de "palo/árbol/bosque" / $\mathrm{k}^{\mathrm{w}} \mathrm{aw} /$, lo cual solamente funcionaría en náhuatl; de ser así, el signo pictórico compuesto sería un glotograma.

El siguiente signo en nuestra lista de posibles glotogramas tiene la clave hui29r_04. Se trata de un grafema que representa una pierna humana. Se encuentra sobre la cabeza de un señor, quien aparece sentado en su asiento con respaldo y piel de jaguar. Parece que se trata de la ascensión del señor tenochca Moteuczoma Xocoyotzin, ya que en la misma sección, que corresponde al año 1502, se puede observar un conjunto de signos gráficos que registra la muerte de su antecesor Ahuítzotl. Dos glosas en otomí, una más extensa en la parte superior de la página y otra colocada al lado del grafema de la pierna, expresan el nombre de este señor: Etseyahmü, "señor enojado". ${ }^{52}$ Otra glosa registra el antropónimo náhuatl equivalente: Moteuczoma, "señor enojado". El signo de la pierna no es usual en las representaciones del nombre de este señor en otros manuscritos centromexicanos. Generalmente se empleaba el grafema de la diadema señorial de turquesa, a veces acompañado con joyas del mismo material. ${ }^{53}$ En el Códice de Huichapan el signo de la diadema y las joyas se reserva para el primer señor de este nombre, Moteuczoma Ilhuicamina. La pierna podría expresar la primera sílaba del segundo nombre de Moteuczoma Xocóyotl, ya que el morfema

nario de mejicanismos, razonado; comprobado con citas de autoridades; comparado con el de americanismos y con los vocabularios provinciales de los más distinguidos diccionaristas hispanamericanos, 15a. ed., México, Editorial Porrúa, 1992, 316.

${ }^{52}$ La ortografía ha sido modernizada; las glosas originales dicen "etzeyahmu" y "etzeyahmü" (véase el apéndice 2).

${ }^{53}$ The Codex Mendoza, op. cit., 15v. 
xo- (xo) significa "pie" en una larga serie de palabras compuestas. ${ }^{54}$ Xocoyotl (xōcoyōtl) significa "hijo menor" y no parece tener una relación semántica directa con $x o$-, "pie". ${ }^{55}$ Por ello es posible que el grafema de la pierna tenga un valor glotográfico, por el juego cuasihomófono (hay un contraste en duración vocálica) entre xo-, "pie" y la primera sílaba de xocoyotl, "hijo menor". Pero hay otro posible juego homófono, esta vez en otomí. En el vocabulario trilingüe de fray Alonso Urbano, aproximadamente contemporáneo con el Códice de Huichapan, se encuentra la siguiente entrada: "Rodilla de la pierna. tlanquaitl. tetepontli — anyähmü”. ${ }^{56} \mathrm{El}$ morfema otomí yähmü, "rodilla", es fonéticamente muy similar a las últimas dos sílabas del antropónimo Etseyahmü, "señor enojado"; sólo hay un contraste de nasalización en una de las vocales. Así es que tenemos lecturas glotográficas factibles del grafema de la pierna, basadas en juegos cuasihomófonos en náhuatl y en otomí. Quizá ambas lecturas pasaron por la mente del escritor bilingüe que pintó este signo.

El otro signo antropónimo en nuestra lista de posibles glotogramas, con la clave hui29v_04, representa agua cayendo del cielo: cuatro chorros de agua parten de cuatro cuentas azules y convergen en una cuenta blanca y dos caracolitos del mismo color. La ubicación de este signo, arriba de la cabeza de un posible bulto mortuorio femenino, permite reconocerlo como signo antroponímico. Junto a este signo hay una glosa de una sola palabra en náhuatl: Tecihuatl. ${ }^{57}$ Este vocablo tiene dos posibles traducciones: "la mujer de piedra" y "la mujer casada". La segunda implica un error gramatical, ya que faltaría el sufijo posesivo -uh (tecihuauh); aún así la considero como hipótesis, por el hecho de que el autor de los textos alfabéticos del Códice de Huichapan hablaba el náhuatl como segundo idioma.

${ }^{54}$ Karttunen, op. cit., 328; Alonso de Molina, Vocabulario en lengua mexicana y castellana, México, Casa de Antonio de Espinosa, 1571, 160r-161v.

${ }^{55}$ Karttunen, op. cit., 330; Molina, Vocabulario en lengua mexicana y castellana, op. cit., $160 \mathrm{v}$.

${ }^{56}$ Alonso Urbano, Arte breve de la lengua otomi y vocabulario trilingüe español-náhuatlotomí, facsímil del ms. de 1605, estudio de René Acuña, México, Instituto de Investigaciones Filológicas, Universidad Nacional Autónoma de México, 1990, 372v. La forma moderna en el Mezquital, es ñähmu (Hernández/Victoria/Sinclair Crawford, op. cit., 254).

${ }^{57}$ He modernizado la ortografía; la glosa dice “Teziuatl” (véase el apéndice 2). 
Pero ninguna de las dos traducciones tiene una relación semántica aparente con el signo de la lluvia. Hay un posible vínculo entre el signo pintado y la glosa: el juego cuasihomófono entre la palabra tecihuitl, "granizo", y Tecihuatl. Si así fuera, el signo antroponímico sería un glotograma.

Hay cuatro signos numéricos entre los posibles glotogramas de este manuscrito, registrados con las claves hui19v_10, hui30r_07, hui34r_03 y hui34r_06. Los cuatro representan mechones de pelo negro, muy estilizados, que a primera vista parecen plumas o pinos. Se trata del signo que en otros manuscritos pintados del Centro de México tiene el significado de “400", en unos contextos, y de "pelo" en otros. En náhuatl, la voz tzontli significa "cabello" y la misma palabra, en composición con el morfema que significa "1" (centzontli), significa " 400 ", literalmente "una cabellera". ${ }^{58} \mathrm{El}$ signo del pelo, cuando se usa para el número 400, encierra un juego homófono en náhuatl. Pero este juego tiene también una dimensión semántica, porque el grafema del mechón de pelo y el número 400 comparten el concepto de "muchos". La palabra otomí para "400", andamao, no se parece a ninguna de las palabras en este idioma para "cabello" o "pelo". ${ }^{99}$ Por ello el grafema numérico que estamos examinando tiene más sentido en náhuatl que en otomí, por el juego homófono mencionado. Estamos sobre la borrosa frontera entre la glotografía y la semasiografía. Hablando con rigor, el signo es semasiográfico, porque tiene sentido en náhuatl y en otomí. El signo hui19v_10, uno de los tres que estamos analizando aquí, se asocia con una glosa con la palabra odamao, " $400 " .{ }^{60}$ La metáfora del pelo para la idea de "muchos" trasciende la frontera lingüística, a pesar de la falta de un juego homófono en otomí, lo que debilita la hipótesis de que este signo sea un glotograma.

${ }^{58}$ Alonso de Molina, Vocabulario en lengua castellana y mexicana, México, Casa de Antonio de Espinosa, 1571, 119r; Molina, Vocabulario en lengua mexicana y castellana, op. cit., 153v. Centzontli también significaba, por extensión, "una mata de ortaliza, o de yerva" (ibid., 18r).

${ }^{59}$ Urbano, op. cit., 69r, 330v, 420v.

${ }^{60}$ Odamao es una variante de Andamao. La raíz es damao; $o$ - y an-son prefijos sustantivos singulares. 
El último signo de nuestra lista de posibles glotogramas tiene el número de clave hui14v_04. Consta de un rectángulo con tres elementos rectilíneos, parecidos a la letra $C$ invertida. Se trata del conocido signo que representa la sementera. En este caso podría ser un signo antroponímico. Usualmente los signos de esta clase se encuentran al lado de las cabezas de las representaciones de personas. El signo hui14v_04 se encuentra arriba de un signo antropomorfo, pero en este caso la representación humana es la de un hombre decapitado. Su cabeza, con una cuerda en el cuello y chorros de sangre, se encuentra a un lado de sus pies. En lugar de taparrabo tiene una faja en la cintura y dos palos entre sus piernas. En la glosa otomí correspondiente hay un antropónimo que se relaciona con el signo pintado: Eyänmahai . Esta palabra tiene dos posibles traducciones, debido a la bivalencia de la sílaba yä: "el señor de la tierra" y "cabeza en la tierra" ${ }^{61}$ La primera traducción parece más razonable para el nombre de una persona, pero el hecho de que la cabeza de esta persona aparece literalmente en la tierra evidentemente se relaciona con la segunda. Fray Alonso Urbano registra la frase otomí acäbäte amahái, "matar", que también se relaciona con los signos que estamos examinando. ${ }^{62}$ Lo que vincula el signo de la sementera con las expresiones verbales Eyänmaha $i$ y acäbäte amaha $i$ es el hecho de que se representa gráficamente la tierra, hại en otomí. ${ }^{63}$ Es probable que el

${ }^{61}$ La ortografía ha sido modernizada; la glosa dice "eyänmahoy" (véase el apéndice 2).

${ }^{62}$ Urbano, op. cit., $283 \mathrm{r}$.

${ }^{63}$ Urbano (op. cit., 402r, 402v) escribe este morfema "hôy" (hại). Sabemos que la vocal ô de Urbano representa el fonema /â/ porque en tres variantes modernas del otomí, la palabra para "tierra" es hại (Ewald Hekking y Severiano Andrés de Jesús, Diccionario español-otomi de Santiago Mexquititlán, Querétaro, Centro de Estudios Lingüísticos y Literarios, Universidad Autónoma de Querétaro, 1989, 183; Yolanda Lastra, El otomí de Toluca, México, Instituto de Investigaciones Antropológicas, Universidad Nacional Autónoma de México, 1992, 197; Katherine Voigtlander y Artemisa Echegoyen, Luces contemporáneas del otomi. Gramática del otomi de la Sierra, 2a. reimpresión, México, Instituto Lingüístico de Verano, 1985, 36). En el dialecto del Mezquital la vocal $\underline{a}$ se ha convertido en $a$, en general, por lo que se usa la palabra hai (Hernández, Victoria y Sinclair, op. cit., 74). Algo similar ha sucedido en la variante de Ixtenco, Tlaxcala, pero el fonema $\underline{a}$ se ha convertido en $o$, por lo que allí se dice hoi (Yolanda Lastra, El otomí de Ixtenco, México, Instituto de Investigaciones Antropológicas, Universidad Nacional Autónoma de México, 1997, 21, 394). Estos cambios fonológicos no son sorprendentes, porque la vocal $\underline{a}$ tiene una pronunciación entre la /a/ y la /o/. Véase el cuadro ortográfico 
signo pintado "sementera" exprese semasiográficamente el antropónimo Eyänmaha $i$, con el significado "el señor de la tierra", pero creo que es conveniente mantener, en nuestra mesa de discusión, la hipótesis de que el signo tenga una función verbal, como referencia a la ejecución de un hombre. Una vez más estamos en la borrosa frontera entre la semasiografía y la glotografía. Si bien, la secuencia fonética ha $i$ expresa conceptos distintos, éstos pertenecen al mismo campo semántico (matar es tirar a la tierra). Lo que parece ser un juego homófono en realidad no lo es, por tratarse del mismo morfema.

\section{Conclusiones}

A través del análisis de los posibles signos glotográficos en el Códice de Huichapan, hemos visto que la tarea no es sencilla. Hay muchas incógnitas que hacen imposible la resolución definitiva de cada caso. Algunas de las hipótesis expuestas son más probables que otras, pero ninguna es segura. En cuanto a los vínculos entre los signos pintados y las lenguas, hemos visto que hay posibilidades de lecturas glotográficas en otomí y en náhuatl. Esto no es extraño, considerando el bilingüismo de la clase gobernante en el valle del Mezquital durante el periodo Novohispano Temprano. Ambas comunidades lingüísticas compartían el mismo sistema de comunicación visual durante siglos. La escritura centromexicana posee la flexibilidad necesaria para crear signos glotográficos, mediante los juegos homófonos, en cualquier lengua nativa de esta región. No debe perderse de vista, sin embargo, que la gran mayoría de los signos gráficos de carácter pictórico que se encuentran en este manuscrito son semasiogramas, por lo que podían ser leídos en cualquiera de las lenguas que se hablaban en el Centro de México.

en Wright, Los otomies, op. cit., vol. 2, 233. Una versión preliminar, menos precisa que ésta, fue publicada en Wright, "Signos toponímicos", op. cit., 53; otra versión, corregida y ampliada, se dio a luz en David Charles Wright Carr, Fonemas otomies que no existen en el castellano, ed. digital, París, Editions Sup-Infor (http://www.sup-infor.com; actualización: 19 de septiembre de 2011; acceso: 11 de noviembre de 2011). 
Apéndice i: Posibles glotogramas en el Códice DE HUICHAPAN ${ }^{64}$

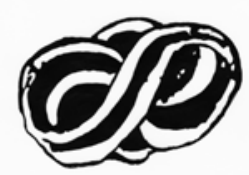

hui05v_06

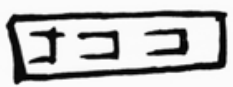

hui14v_04

hui22r_07
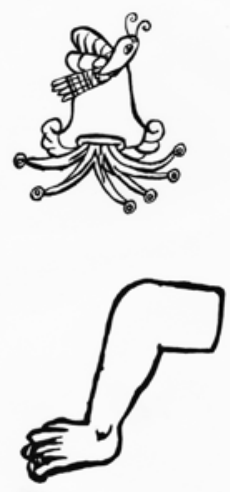

hui29r_04
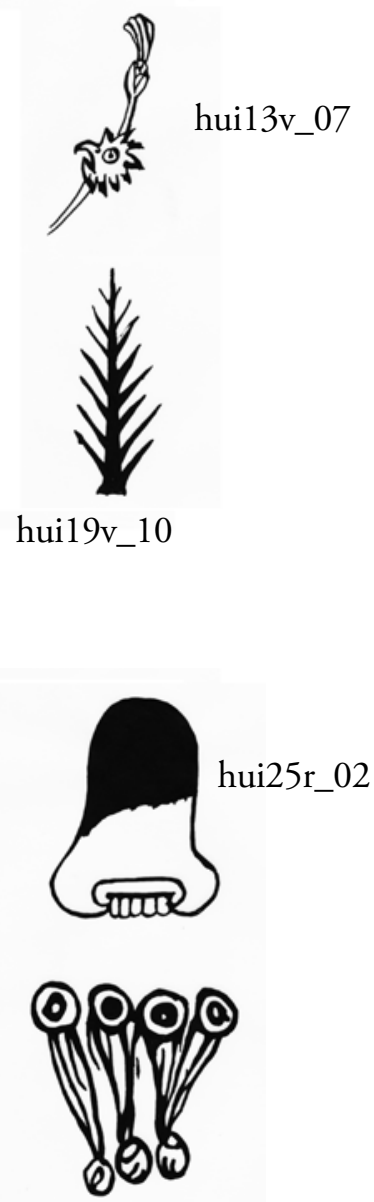

hui29v_04

${ }^{64}$ Dibujos del autor que refieren al Códice de Huichapan, comentado por Alfonso Caso, facsímil del ms., estudios de Alfonso Caso y Óscar Reyes Retana, México, Telecomunicaciones de México, 1992, láminas 10, 26, 28, 38, 43, 49, 57, 58, 59, 61, 63, 64 y 67. 

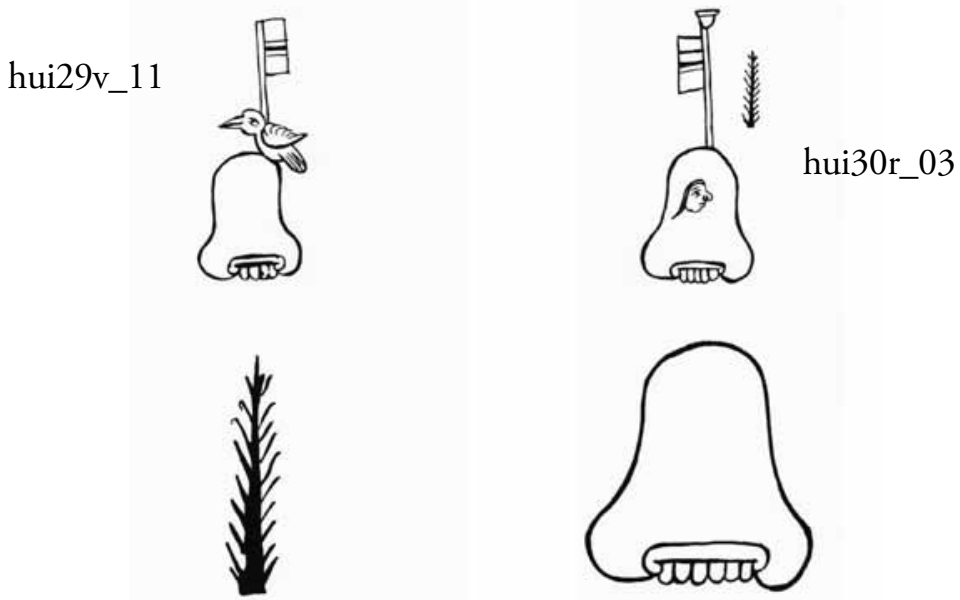

hui30r_07

hui31r_11
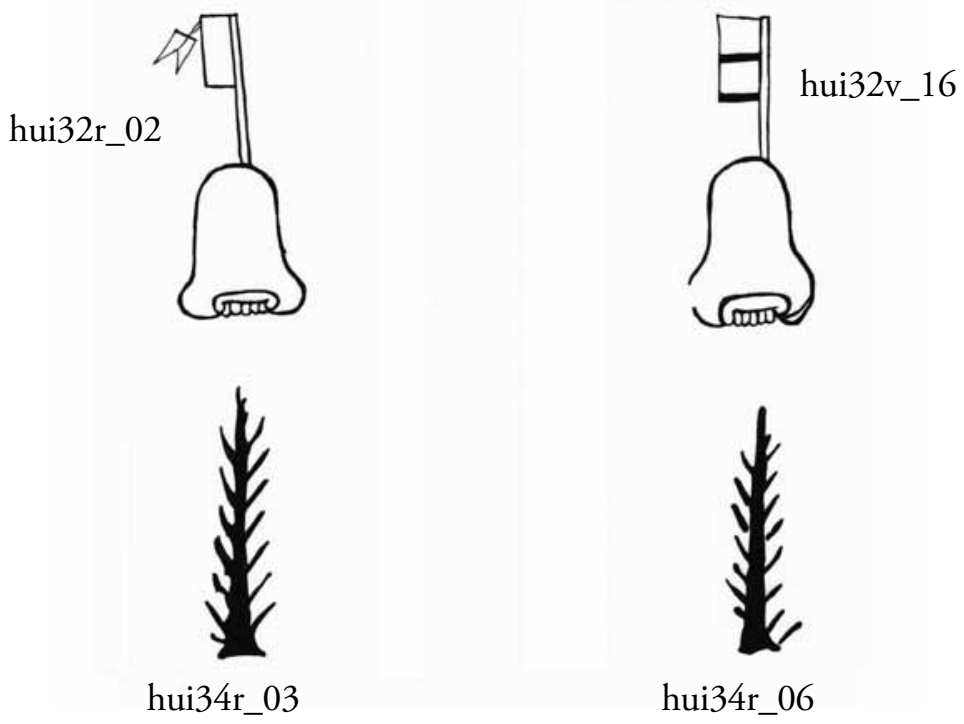
Apéndice 2. AnÁlisis morfológicos de las glosas ASOCIADAS CON LOS POSIBles GLOTOGRAMAS DEL CÓDICE DE HUICHAPAN ${ }^{65}$

Signo gráfico: hui05v_06

Glosa asociada, folio 5v (otomí): “antomeni”

(1) antomëni; (2) antomeni

(1) an + to + mëni; (2) an + to + meni

(1) prefijo sustantivo singular · sustantivo: "piedra" · sustantivo: "pariente"; (2) prefijo sustantivo singular · sustantivo: "piedra” · verbo: "lavar"

(1) “Antomëni, 'la piedra de los parientes'; (2) Antomeni, 'la piedra de lavar".

Signo gráfico: hui13v_07

Glosa asociada, folio 13v (otomí): "egaxuntäxi/egaxunntaxi” egaxuntäxi

$e+g a+($ xuni $-i)+$ täxi

prefijo antroponímico · preposición: "de" · sustantivo: "águila” · sustantivo: "mazorca tierna"

“Egaxunntäxi, 'mazorca tierna del águila”.

Glosa asociada, folio 13v (náhuatl): "quauhxilotl"

(1) cuāuhxīlōtl; (2) cuauhxīlōtl

(1) (cuāuhtli - tli) + xīlōtl; (2) (cuahuitl - itl) + xīlōtl

(1) sustantivo: "águila" · sustantivo: "mazorca tierna"; (2) sustantivo: "bosque/árbol/madera/palo" · sustantivo: "mazorca tierna" (1) "Cuauhxilotl, 'la mazorca tierna del águila"; (2) "Cuauhxilotl, 'la mazorca tierna del bosque/del árbol/de la madera/del palo’ (el cuajilote)".

${ }^{65}$ Estos análisis se tomaron de los apéndices vir y viII de mi tesis doctoral (Wright, Los otomies, op. cit., vol. 2, 307-357. Hay varias correcciones en el presente estudio. 
Signo gráfico: hui14v_04

Glosa asociada, folio 14v (otomí): "eyänmahoy”

eyänmahại

$\mathrm{e}+\mathrm{yä}+\mathrm{n}+\mathrm{ma}+$ hại

prefijo antroponímico · sustantivo: "señor/cabeza" · fonema epentético (o prefijo sustantivo singular sincopado) $\cdot$ prefijo locativo $\cdot$ sustantivo: "tierra"

“Eyänmahai i, (1) 'el señor de la tierra'; (2) 'cabeza en la tierra”".

Signos gráficos: hui19v_10, hui30r_07, hui34r_03 y hui34r_06

Glosa asociada, folios 19v, 30r (otomí): "odamao/odâmaoh” odamao

o + damao

prefijo sustantivo singular · número: “400”

odamao, “400"

Signo gráfico: hui22r_07

Glosa asociada, folio 22r (otomí): "anttaxttoho"

(1) ant'axt'oho; (2) ant'äxt'oho

(1) an + (t'axi-i) + t'oho ; (2) an + (t'äxi-i) + t'oho

(1) prefijo sustantivo singular · adjetivo: "blanco" · sustantivo: "cerro"; (2) prefijo sustantivo singular · sustantivo: "langosta" · sustantivo: "cerro"

(1) “Ant'axt’oho, 'el cerro blanco"”; (2) “Ant'äxt’oho, 'el cerro de la(s) langosta(s)"”.

Signos gráficos: hui25r_02 y hui31r_11

Glosas asociadas, folios ff. 25r y 31r (otomí): "anbottoho" an'bot'oho

an + 'bo + t' $\underline{\text { oho }}$ 
(1) prefijo sustantivo singular · adjetivo: "negro" · sustantivo: "cerro"; (2) prefijo sustantivo singular · partícula abundancial · sustantivo: "cerro"

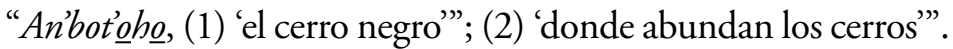

Signo gráfico: hui29r_04

Glosas asociadas, folios 29r (1502); 29v (1503); 32r (1517) (otomí): "etzeyahmu/etzeyahmü/egatzeyahmü"

etseyahmü

$\mathrm{e}+\mathrm{ts} \underline{\mathrm{e} y a}+\mathrm{hmü}$

prefijo antroponímico · verbo: "enojarse" · sustantivo: "señor"

"Etseyahmü, 'señor enojado"”.

Glosa asociada, folio 29r (náhuatl): "Motecçuma"

motēuczōmah

mo + (tēuctli - tli $)+$ zōmā $(\bar{a}>a)+h$

prefijo reflexivo · sustantivo: "señor" · verbo: "hacer gesto de enojado" · sufijo pretérito

"Moteuczoma, 'señor enojado".

Signo gráfico: hui29v_04

Glosa asociada, folio 29v (náhuatl): "Teziuatl”

(1) tecihuātl; (2) tēcihuātl

(1) (te - tl) + cihuātl; (2) tē + cihuātl

(1) sustantivo: "piedra" - sustantivo: mujer; (2) prefijo posesivo indefinido humano · sustantivo: mujer.

(1) "Tecihuatl, "la mujer de piedra"; (2) "Tecihuatl, 'la mujer casada".

Signos gráficos: hui29v_11, hui30r_03, hui32r_02 y hui32v_16

Glosas asociadas, folios 29v y 30r (otomí): “amabexte anttoho/ amabex[borrado/roto]"

ama'bexte ant'oho

ama + 'bexte an + t'oho 
prefijo locativo · sustantivo: "bandera" · prefijo sustantivo singular · sustantivo: "cerro"

"Ama'bexte Ant’oho, "lugar de banderas, el cerro".

Glosa asociada, folio 30r (náhuatl): "Çopantepec"

(1) zōpāntēpec; (2) zōpantēpec; (3) tzompāntēpec

(1) $($ zōtl $-\mathrm{tl})+($ pāntli - tli $)+($ tèpetl $-\mathrm{tl})+(\mathrm{co}-\mathrm{o}) ;(2)($ zōtl $-\mathrm{tl})+$ pan + (tēpetl $-\mathrm{tl})+(\mathrm{co}-\mathrm{o}) ;(3)($ tzontli $-\mathrm{tli})(\mathrm{n}>\mathrm{m})+($ pāntli - tli $)$ $+($ tēpetl $-\mathrm{tl})+(\mathrm{co}-\mathrm{o})$

(1) sustantivo: "tela" - sustantivo: "bandera/estandarte" - sustantivo: "cerro" · sufijo locativo: "a/dentro de/en/en el tiempo de/por/sobre"; (2) sustantivo: "tela" · posposición: "acerca de/con/de/dentro de/durante/en/en el lugar de/en el tiempo de/en la superficie de/ por/sobre" · sustantivo: "cerro" · sufijo locativo: "a/dentro de/en/en el tiempo de/por/sobre"; (3) sustantivo: "pelo" · sustantivo: "bandera/estandarte" · sustantivo: "cerro" · sufijo locativo: "a/dentro de/en/ en el tiempo de/por/sobre"

(1) "Zopantepec, 'en el cerro de la bandera de tela"; (2) "Zopantepec, 'en el cerro del lugar de tela"; (3) "Tzompantepec, 'en el cerro de la bandera de pelo"'.

\section{REFERENCIAS CITADAS}

Anders, Ferdinand, Maarten E. R. G. N. Jansen y Gabina Aurora PÉrez Jiménez, Origen e historia de los reyes mixtecos. Libro explicativo del llamado Códice vindobonensis. Codex vindobonensis mexicanus 1. Österreichische Nationalbibliothek, Viena, Madrid, Graz, México, Sociedad Estatal Quinto Centenario, Akademische Druck-und Verlagsanstalt, Fondo de Cultura Económica, 1992.

Andrews, Carol, The Rosetta Stone, 20a. reimpresión, Londres, British Museum Press, 1998.

ANDrews, J. Richard, Introduction to classical Nahuatl. Revised edition, Norman, University of Oklahoma Press, 2003.

Bernard, H. Russell, Social research methods. Qualitative and quantitative approaches, Thousand Oaks, Londres, New Delhi, Sage Publications, 2000. 
Boone, Elizabeth Hill, "Introduction: Writing and recording knowledge", en Writing without words. Alternative literacies in Mesoamerica \& the Andes, Elizabeth Hill Boone y Walter D. Mignolo, editores, Durham, Londres, Duke University Press, 1994, 3-26.

, Stories in red and black. Pictorial histories of the Aztecs and Mixtecs, Austin, University of Texas Press, 2000.

Chanquía, Diana, Lo enunciable y lo visible, México, Consejo Nacional para la Cultura y las Artes, 1998.

The Codex Mendoza, facsímil del ms., vol. 3, Frances F. Berdan y Patricia Rieff Anawalt, editoras, Berkeley, Los Ángeles, Oxford, University of California Press, 1992.

Códice de Huichapan, Biblioteca Nacional de Antropología e Historia, México, Testimonios Pictográficos, núm. 35-60, c. 1632.

Códice de Huichapan, ed. digital, David Charles Wright Carr, editor, París, Editions Sup-Infor (http://www.sup-infor.com; actualización: 18 de junio de 2011; acceso: 11 de noviembre de 2011).

Códice de Huichapan, comentado por Alfonso Caso, facsímil del ms., estudios de Alfonso Caso y Óscar Reyes Retana, México, Telecomunicaciones de México, 1992.

Códice Moctezuma o Matrícula de tributos, facsímil del ms., Luis Reyes García, editor, Graz, México, Akademische Druck-und Verlagsanstalt, Fondo de Cultura Económica, 1997.

Coe, Michael D., Breaking the Maya code, Nueva York, Thames and Hudson, 1992.

Coe, Michael D. y Mark Van Stone, Reading the Maya glyphs, Londres, Nueva York, Thames and Hudson, 2001.

Collier, Mark y Bill Manley, How to read Egyptian hieroglyphs. A step-by-step guide to teach yourself, Londres, British Museum Press, 1998.

Copleston, Frederick, A history of philosophy. Volume III. Late mediaeval and renaissance philosophy. Part I. Ockham to the speculative mystics, Garden City, Image Books, 1963.

Corominas, Joan y José A. Pascual, Diccionario crítico etimológico castellano e hispánico, 1a. reimpresión de la 1a. ed., 6 vols., Madrid, Editorial Gredos, 1983-1985. 
Coulmas, Florian, Writing systems. An introduction to their linguistic analysis, Cambridge, Cambridge University Press, 2003.

, The writing systems of the world, reimpresion, Oxford, Cambridge, Blackwell Publishers, 2003.

Davies, Claude Nigel Byam, Los señorios independientes del imperio azteca, México, Instituto Nacional de Antropología e Historia, 1968.

Diccionario de la lengua española, 22a. ed. con adelantos de la 23a. ed., Madrid, Real Academia Española, 2005 (http://buscon.rae. es/diccionario/drae.htm; actualización: abril de 2005; acceso: 11 de noviembre de 2011).

Echegoyen, Artemisa, "Códice de Huichapan, paleografía y traducción por Lawrence Ecker” (reseña), en Estudios de Cultura Otopa$m e$, Instituto de Investigaciones Antropológicas, Universidad Nacional Autónoma de México, núm. 3, 2002, 249-253.

ECKer, Lawrence, Códice de Huichapan, paleografía y traducción, Yolanda Lastra y Doris Bartholomew, eds., México, Instituto de Investigaciones Antropológicas, Universidad Nacional Autónoma de México, 2001.

, "Compendio de gramática otomí (introducción a un diccionario otomí-espańol)", en Anales del Instituto Nacional de Antropología e Historia, época 6, vol. 4, 1952, 121-174.

Elson, Benjamin F.; Velma B. Pickett, Beginning morphology and syntax (revised), Dallas, Summer Institute of Linguistics, 1988.

FisCHER, Henry George, "The origin of Egyptian hieroglyphs", en The origins of writing, Wayne M. Senner, editor, reimpresión de la 1a. ed., Lincoln, Londres, University of Nebraska Press, 1991, 59-76.

Gelb, Ignace J., Historia de la escritura, Alberto Adell, traductor, Madrid, Alianza Editorial, 1976.

Gómez DE Silva, Guido, Breve diccionario etimológico de la lengua española, 2a. ed., México, El Colegio de México, Fondo de Cultura Económica, 1998.

Green, M. W., "Early cuneiform", en The origins of writing, Wayne M. Senner, editor, reimpresión de la 1a. ed., Lincoln, Londres, University of Nebraska Press, 1991, 43-57. 
Hahner, Jeffrey C., Martin A. Sokoloff, Sandra L. SAlisch, Speaking clearly. Improving voice and diction, 5a. ed., Boston, Burr Ridge, Dubuque, Madison, Nueva York, San Francisco, St. Louis, McGraw-Hill, 1997.

Harris, John F. y Stephen K. Stearns, Understanding Maya inscriptions, Filadelfia, The University Museum of Archaeology and Anthropology, University of Pennsylvania, 1992.

HeKkIng, Ewaldr y Severiano ANDrés DE Jesús, Diccionario españolotomi de Santiago Mexquititlán, Querétaro, Centro de Estudios Lingüísticos y Literarios, Universidad Autónoma de Querétaro, 1989.

Hernández Cruz, Luis, Moisés Victoria Torquemada y Donald Sinclair Crawford, Diccionario del hñ̈̈hñu (otomi) del Valle del Mezquital, estado de Hidalgo, 2a. reimpresión, México, Instituto Lingüístico de Verano, 2004.

“The international phonetic alphabet (revised to 2005)", en The International Phonetic Association (http://www.langsci.ucl.ac.uk/ ipa/IPA_chart_(C)2005.pdf; actualización: 2005; acceso: 11 de noviembre de 2011).

Karttunen, Frances, An analytical dictionary of Nahuatl, 2a. ed., Norman, University of Oklahoma Press, 1992.

Lastra, Yolanda, "Códice de Huichapan”, en Códices del estado de Hidalgo/State of Hidalgo codices, Laura Elena Sotelo Santos, Víctor Manuel Ballesteros García y Evaristo Luvián Torres, coords., Pachuca, Universidad Autónoma del Estado de Hidalgo, 2001, 42-47.

, "El códice otomí de San Mateo Huichapan", en Arqueología Mexicana, Editorial Raíces, Instituto Nacional de Antropología e Historia, vol. 13, núm. 73, 2005, 32-37.

, Elotomi de Toluca, México, Instituto de Investigaciones Antropológicas, Universidad Nacional Autónoma de México, 1992. , Elotomi de Ixtenco, México, Instituto de Investigaciones Antropológicas, Universidad Nacional Autónoma de México, 1997. El libro de las tasaciones de pueblos de la Nueva España. Siglo XVI, Francisco González de Cossío, editor, México, Archivo General de la Nación, 1952. 
López YePes, Joaquín, Catecismo y declaración de la doctrina cristiana en lengua otomí, con un vocabulario del mismo idioma, México, Oficina del Ciudadano Alejandro Valdés, 1826.

LounsBury, Floyd G., "The ancient writing of Middle America", en The origins of writing, Wayne M. Senner, editor, reimpresión de la 1a. ed., Lincoln, Londres, University of Nebraska Press, 1991, 203-237.

Malmberg, Bertil, Los nuevos caminos de la lingüistica, 20a. ed., Juan Almela, traductor, México, Siglo Veintiuno Editores, 1997. Marcus, Joyce, Mesoamerican writing systems. Propaganda, myth, and history in four ancient civilizations, Princeton, Princeton University Press, 1992.

Molina, Alonso de, Vocabulario en lengua castellana y mexicana, México, Casa de Antonio de Espinosa, 1571.

, Vocabulario en lengua mexicana y castellana, México, Casa de Antonio de Espinosa, 1571.

Nuevo diccionario enciclopédico Espasa, Madrid, Espasa Calpe, 1998.

Popper, Karl Raimund, Conjectures and refutations. The growth of scientific knowledge, reimpresión de la 5a. ed., Londres y Nueva York, Routledge, 2000.

Sampson, Geoffrey, Writing systems. A linguistic introduction, Stanford, Stanford University Press, 1985.

Santamaría, Francisco J., Diccionario de mejicanismos, razonado; comprobado con citas de autoridades; comparado con el de americanismos y con los vocabularios provinciales de los más distinguidos diccionaristas hispanomericanos, 15a. ed., México, Editorial Porrúa, 1992.

SCHELE, Linda, "Introduction to reading Maya hieroglyphs", en Notebook for the XXVth Maya Hieroglyphic Forum at Texas, edición xerográfica, 1a. parte, Austin, Maya Workshop Foundation, 2001, 1-75.

Smith, Michael Ernest y Frances F. Berdan, "Province descriptions", en Aztec imperial strategies, Washington, Dumbarton Oaks, 1996, 265-349.

Soustelle, Jacques, "Deux contes otomis", en Journal de la Société des Américanistes, serie nueva, vol. 27, 1935, 1-19. 
Stresser-PÉAn, Guy, El Códice de Xicotepec. Estudio e interpretación, Puebla, México, Gobierno del Estado de Puebla, Centre d'Etudes Mexicaines et Centraméricaines, Fondo de Cultura Económica, 1995.

Swadesh, Morris, El lenguaje y la vida humana, 8a. reimpresión, México, Fondo de Cultura Económica, 1995.

TAube, Karl Andreas, "The writing system of ancient Teotihuacan", en Ancient America, Center for Ancient American Studies, núm. 1, 2000, 1-56.

Urbano, Alonso, Arte breve de la lengua otomí y vocabulario trilingüe español-nábuatl-otomí, facsímil del ms. de 1605, estudio de René Acuńa, México, Instituto de Investigaciones Filológicas, Universidad Nacional Autónoma de México, 1990.

Vignaux, Paul D., "Ockham, William of", en Encyclopedia Britannica CD 99, ed. digital, Chicago, Encyclopædia Britannica, 1998.

Voigtlander, Katherine, Artemisa Echegoyen, Luces contemporáneas del otomí. Gramática del otomi de la Sierra, 2a. reimpresión, México, Instituto Lingüístico de Verano, 1985.

WALlis, Ethel Emilia, “Toponimia otomí del valle del Mezquital”, en Revista Mexicana de Estudios Antropológicos, México, Sociedad Mexicana de Antropología, vol. 14, 1a. parte, 1956, 153-160.

Wright CARr, David Charles, "Comunicación gráfica en el Códice de Huichapan”, en Memoria del IV Coloquio Nacional sobre Otopames, David Charles Wright Carr, coord., Guanajuato, Departamento de Historia, División de Ciencias Sociales y Humanidades, Campus Guanajuato, Universidad de Guanajuato, Comité Académico de los Coloquios Internacionales sobre Otopames, 2010, 61-75.

Fonemas otomíes que no existen en el castellano, ed. digital, París, Editions Sup-Infor (http://www.sup-infor.com; actualización: 19 de septiembre de 2011; acceso: 11 de noviembre de 2011).

Lectura del nábuatl. Fundamentos para la traducción de los textos en nábuatl del periodo Novohispano Temprano, México, Instituto Nacional de Lenguas Indígenas, 2007. 
, Los otomies: cultura, lengua y escritura, tesis, 2 vols., Zamora, Doctorado en Ciencias Sociales, El Colegio de Michoacán, 2005.

"Signos toponímicos en el Códice de Huichapan", en Estudios de Cultura Otopame, México, Instituto de Investigaciones Antropológicas, Universidad Nacional Autónoma de México, núm. 2, 2000, 45-72.

"Writing" en Encyclopedia Britannica CD 99, ed. digital, Chicago, Encyclopædia Britannica, 1998.

FeCha De RECEPCión Del aRTí́culo: 14 de junio de 2011

FECHA DE ACEPTACIÓN Y RECEPCIÓN DE LA VERSIÓN FINAL: 24 noviembre de 2011 